\title{
Bricklaying with Mortar: Prosodic Orientation to English Language Teaching
}

\author{
Gurpal S. Rana \\ Lovely Professional University, Punjab
}

\begin{abstract}
This paper explores the use of a prosody based model of English language teaching, which focuses on enhancing "sophisticated communicative competence" of learners, while weighing in divergent ideas which might scuttle this pedagogical initiative. It explores four different dimensions: 1) Non-native identity of the language teacher as a stumbling block, 2) fallacy of assumption about automatic acquisition of prosodic attributes, 3) misperception about prosody being a mere academic exercise, and 4) defying "critical period hypothesis" underlying biological constraints in acquisition of language nuances.

Key words: prosodic orientation, suprasegmentals, pragmatic fossilization, critical period hypothesis, communicative competence
\end{abstract}

Alice: Would you tell me, please, which way I ought to go from here? The Cheshire Cat: That depends a good deal on where you want to get to.

Alice: I don't much care where -

The Cheshire Cat: Then it doesn't matter which way you go.

Lewis Carroll, Alice in Wonderland

\section{Introductory Overview}

Prosody is a generic term which comprises suprasegmental variations in a speech with specific intended purposes to achieve more clarity and strength in communication while using various tools of spoken language - changing levels of intonation, variable patterning of pitch variations, loudness manipulation, strategic placement of pauses and all of voice modulated nuances. This paper primarily focuses on speech variations which result in enhancement of meanings.

Brick and mortar analogy is used here to emphasize fusional attributes of mortar giving an extraordinary strength to brick laying process in the same way when prosody binds the segmental bricks of consonants and vowels sounds of the English language. The paper explores imperative focus of prosodic elements of speech in language teaching as well as its learning, which needs to be simultaneously strengthened with segmental components of speech. Prosodic orientation becomes much more important keeping in mind the dual impact it has in everyday conversation and more so in classroom discourse where near-complete reception of delivered content is important. And this duality comes into play where it is not only the language teacher who employs prosodic structural variations suited to organize information but also "... [the] listeners use prosodic cues to parse incoming information and predict upcoming discourse structure" (Pickering, 1999, p. 4). 
Prosodic orientation is to be recognized as a necessary tool to "sophisticated communicative competence" (Pickering, 1999, p. 1) along with segmental components of speech. This orientation has multifold benefits where it is not only about enabling access to linguistic information through various structural clustering of variable lengths, or providing newer information in a continuous discourse, or disambiguating any stretch of sentences that might leave the listener ambiguous in ascertaining the meaning, but also about providing information beyond linguistic realm, i.e., demographic and mental state of the speaker.

Prosodic orientation inherently does give representation, especially in classroom discourse, to multiple communicative cues at all levels, i.e., lexical, arrangement of words, prosodic and paralinguistic. Prosody does have the ability to answer and display the "malleability of meaning" (Romero-Trillo, 2012, p. 117) while travelling from the language user to the listener. It does indicate, in some measures, that all the intended meanings do not reach the comprehension level of the audience for the reasons that either they were not expressed explicitly or there is a lack of receptive skill-set at the receiver's end. This takes us to the core issues of the problem of finding an alternative English language teaching pedagogy.

Suggestions forwarded act as a technique to make a leap forward and fill an existing gap between an approach, which has grammar competence focus to the desired one having focus on interactional communicative competence. Essentially an important aspect of prosodic orientation, while taking language outside the classroom, is its functional role in allowing conversation partners to realize places of transitional role in turn-taking. There would be an array of features available to indicate those transition-places. These can be intonational swings, specific variation in syntax choice, strategic placement of pauses and all other kinds of non-verbal cues. And prosody covers all these components of speech.

Prosodic orientation contributes to the "illocutionary force" (Searle, 1969) of a speech, where different language-dimensions of the speaker get a space. These can be the prevalent state of emotion, inducting contextual relevance of the speech or any of the intended functions of the speech. Individuals exhibiting efficient usage of the language would automatically mean that they possess both segmental and prosodic features of speech; segmental components include consonants and vowels whereas prosodic elements have their overarching reach over these multiple segments such as stress patterns, pitch variation and intonation slides. Functional focus of language over structural parameters has brought some considerable space for prosodic orientation to be incorporated in the syllabus structure.

Though, there are certain inherent flaws in our approach of repeatedly undermining prosodic orientation to English language teaching which results in its disappearance from most of the syllabi designed for students of professional as well as academic courses. This paper delves into reason and misperceptions about prosodic orientation to English language teaching, which need to be addressed before this approach is offered as an alternative.

1. Almost all the language teachers in India are non-native speakers of the target language which certainly affects the courage to take risk of teaching components which they themselves are not much comfortable with. This is one strong reason for the neglect of the prosodic component in English language teaching.

2. The prosodic components are assumed to be learnt by the student on his own unconsciously, so no concerted efforts are made.

3. Prosodic aspect of the language language is seen more of an academic study reserved for higher order of learning for students enrolled with master degree programme and onwards 
that too especially in linguistics. The utilitarian dimension of prosodic orientation discussed in this paper negates the notion of it as a mere academic activity.

4. Somewhere there in our mindset we are still enmeshed in the Lenneberg idea of "critical period hypothesis" (1967) where we assume our students to have either passed that age or may be, they would not get enough of language exposure outside the classroom. This paper validates a need to change in approach to this hypothesis.

This paper attempts, through contemporary trends and tendencies, to rule out these misperceptions while endeavoring for course correction of the course curricula, which is assumed to be the best and the most comprehensive way forward.

\section{Skill-deficit apprehension in language teachers}

In general awareness terms, apprehension of language teacher not using a particular component indicates a skill deficiency as one of the strong reason and no doubt there can be other valid reasons depending on the contextual circumstances. More importantly, even for language teachers themselves, display of prosodic characteristics in speech is seen as an embedded component of language usage and in some ways the level of conscious awareness in order to pass it on to students is found to be largely deficient.

Pickering's dissertation thesis investigating the nature of discourse at the classroom level in "native and non-native speaker" (1999) of the English language did make a strong representation of variable prosodic structures ably supported by acoustic analysis covering various aspects like fundamental frequency contours, intonational patterns, placement of stress at morphological level and frequency of pauses. This amply proves distinct differences in prosodic usage between native and non-native users, and our set of teacher well fall in the latter category.

Larsen-Freeman proposed that the framework for teachers' knowledge base should include a clear understanding of learners, who they are, why they learn, what they need to learn, what motivates them, and how a teacher goes about negotiating the teaching as well as learning activities with them (2003, p. 1). But this remains an incomplete goal to accomplish till the teachers themselves have conscious awareness of prosodic components of speech which come out to be a stumbling block while analyzing students' skill set in speaking, as their speech acts do not offer enough variable manipulations in suprasegmental segment.

Language teaching remained affected by certain handicaps which impede efforts to regularize and incorporate prosodic focus as English Orthography, with exception to punctuation marks or stylized interventions, does not provide any standard symbols to enlist and register speech attributes like International Phonetic Alphabet. This absence of conventional symbol is one of the stumbling blocks which disallows a student to identify, use and understand their active role in speech all the time. This all in turn affect the level of cohesiveness in language learners' discourse. Language usage for a discursive purposes needs to maintain a certain amount of measured unity, and prosody does play an active player "in the coherence of discourse" (Wennerstrom, 2001, p. 3).

The idea about complexities in learner's mind which gets triggered because of prosodic incompetence of the teacher is examined and a comparative analysis of three different sets of language inputs are tested and evaluated on the scales of primary stress: correctly placed, incorrectly placed, or missing entirely (Hahn, 2004). There is somewhat a definitive pattern in phonology, descriptive of stress patterns in particular set of words, identified in a similar category 
on the basis of suffixes, prefixes or word category. In this way we can broadly identify and nominate syllables in a word as having primary, secondary or no stress, this logic remains in force till we are at a word stage in isolation or in citation forms but the dynamics of discourse will decide which particular word will receive an emphasis through stress where as stress of other words will disappear. The results validate the importance of incorporating prosodic components in teaching.

\section{Automaticity of prosodic features in learners learning}

Selinker introduced the concept of an intermediary stage in the development of learners' ability interlanguage (1972), which is built upon Corder's previous work on the nature of language learners' errors. And these two works became the foundational pillars of impetus in research into second-language acquisition. Selinker argued that L2 learners possessed an internal linguistic framework which is neither having all L1 characetistics nor L2 salient features, but something inbetween that the learner was building from his exposure of learning.

Corder made a significant contribution to the science of language where focus lies on discussing and analyzing "learner's errors and their correction" (1967). Before he brought this to language teachers' attention, these errors were seen as having no substantive value and as more of annoying natural occurrences in a language learning process. This resulted in psychological as well as linguistic investigations into these to unravel the mystery of language learning processes. The focus took a paradigmatic turn towards learning rather than teaching. Corder made distinctive distinctions between input and intake, where input is defined as the language available from the learning environment, but intake is that language that finally makes its way forward into the learner's developing communicative competence through the window of "transitional competence" (Corder, 1967, p. 166).

Non-native speakers do come across a stage of stasis, Pragmatic Fossilization (RomeroTrillo, 2002), in their learning process where stagnation starts setting in till it is remedied with specific inputs of metalinguistic awareness. This paper refutes the automaticity notion of prosodic features in second language learner and sees into its characteristics features, its reasons of occurrence and regressive impact on second language learning.

This fossilization might spread itself into other structural components of language where "deviant forms" (Wei, 2008, p. 127) as visualized in the paper studying the causal factors in Chinese students learning English with clear distinguishable tell-tale signs setting into phonological, morphological, syntactic, semantic and pragmatic aspect of language use. All these notions really supported a viewpoint that prosodic features are not picked up unconsciously in a measurable quantity in order to affect performance of the learner to a better level, but rather a concerted approach needs to be followed to make it happen.

\section{Prosodic orientation is mere an academic extension of linguistics}

Research orientation is one aspect where various dimensions of prosody are studied, where relationship with all other subfields of linguistics like phonology, phonetics, morphology, syntax, semantics, pragmatics, discourse is studied. Various researches have unequivocally underpinned the utilitarian importance of prosodic orientation enabling learners' communicative competence. 
A case in point is Underhill's pronunciation focus text cum practice book, Sound Foundations which takes you to the journey of natural progression of language skill set from sounds to words to connected speech. It is a book that brings alive a conscious language teacher in you, to your rightful place as a learner of language teaching with a wealth of self-discovery activities which you can instantly share with your students. The beauty lies in this humanistic approach, which sets you and your students off on a journey of self exploration and discovery. Instantly they will be involved in the process of finding their own English voice - not through drills, mimicking and repetition but rather through awareness, experimentation and curiosity. This book is a testimony to prosodic orientation utility in language classroom.

Another case in point is Kreidler's textbook, Describing Spoken English, which is highly recommended for undergraduate and graduate students whose field of study is English language. The author describes a practical and descriptive introduction to the pronunciation of contemporary English while presuming no prior knowledge of phonetics and phonology. Although theoretically orientated towards generative phonology, theory is minimal and the book is clear, comprehensive and accessible. The book allots five out of twelve topics to the field of prosody underlying importance of prosodic orientation to any language learning course.

\section{Constraints of age in second language learning}

"The critical period hypothesis" (Lenneberg 1967) advocated easiness of second language acquisition before the cerebral lateralization completes itself and therefore any new learning in language would remain affected once an individual remains unexposed to the language. There are many researches done after this hypothesis which supports unequivocally this paradigm of negative correlation of age with language acquistion but this paper will pick some of the interesting findings, equally validated too, supporting the contrary view.

A case study (Snow, 1978) testing the hypothesis studied the naturalistic acquisition of Dutch by English speakers of different age groups, one of 12-15 years and others of 3-5 years. The data assimilated found results contrary to Lenneberg hypothesis, where age groups of 8-10 and 1215 years-olds show much faster learning than $3-5$ years.

A case study extensively studying language acquisition pattern on critical period hypothesis over 2.3 million immigrant speakers for checking two of its corollaries: (1) there is a high level of preparedness for learning in 'that' period, and (2) deficiency of preparedness for learning outside 'that' period. The study made us move towards a direction looking into sociological and educational parameters affecting the learning curve rather than solely the biological reasons.

\section{Conclusion}

The fast emerging need of the hour is to make shift in the way we teach English: it has to be taught as communicative tool rather than a set of structured rules or principles focusing on the cognitive activity. Procedural means are to be governed by the justifiable ends of enhancing functional component of language usage in learners mind. Speech devoid of prosodic characteristics would always not only look and sound more like a monotone but also be lesser on meaning quotients. 
Distinguishing feature-component of learner autonomy is to expect from a learner to have those sufficient skill-set to reproduce thoughts in completely unrehearsed contexts and for the teacher, s/he has to sufficiently provide those learning opportunities to pick nuances of an autonomous user of language while keeping a continual spotlight on the learner. Teaching strategies, methods and approaches are to be thoughtfully planned and executed keeping learner at the center stage rather than teacher holding the happenings in the class. Prosodic orientation to the course will give an edge in comprehensive understanding of the language user.

\section{References}

Corder, S P. (1967). The significance of learner's errors. IRAL-International Review of Applied Linguistics in Language Teaching, 5(1-.4), 161-170.

Diane, L. F. (2000). Techniques and principles in language teaching.

Hahn, L. D. (2004). Primary stress and intelligibility: Research to motivate the teaching of suprasegmentals. TESOL quarterly, 38(2), 201-223.

Hakuta, K., Bialystok E., \& Wiley, E. (2003). Critical evidence: A test of the critical-period hypothesis for second-language acquisition. Psychological Science, 14(1), 31-38.

Kreidler, C. W. (1997). Describing spoken English: an introduction. Psycology Press.

Lenneberg, E.H., Chomsky, N., \& Marx, O. (1967). Biological foundations of language. (Vol. 68). New York: Wiley.

Pickering, L. (1999). An analysis of prosodic systems in the classroom discourse of native speaker and nonnative speaker TAs. Unpublished PhD dissertation. Program in Linguistics, University of Florida, Gainesville.

Reed, B. S. (2006). Prosodic orientation in English conversation. Palgrave.

Trillo, J. R. (2002). The pragmatic fossilization of discourse markers in non-native speakers of English. Journal of Pragmatics, 34(6), 769-784.

Romero-Trillo, J. (Ed.). (2012). Pragmatics and prosody in English language teaching.

(Vol. 15). Springer Science \& Business Media.

Searle, J. R. (1969). Speech acts: An essay in the philosophy of language (Vol. 626). Cambridge university press.

Selinker, L. (1972). Interlanguage. IRAL-International Review of Applied Linguistics in Language Teaching, $10(1-4), 209-232$.

Snow, C. E., \& Hoefnagel-Höhle, M. (1978). The critical period for language acquisition: Evidence from second language learning. Child Development, 1114-1128.

Underhill, A. (2005). Sound foundations. Macmillan Education.

Walsh, S. (2006). Investigating classroom discourse. Routledge.

Wei, X. (2008). Implication of IL fossilization in second language acquisition. English Language Teaching, $1(1), 127$.

Wennerstrom, A. (2001). The music of everyday speech: Prosody and discourse analysis. Oxford University Press.

Gurpal Singh Rana is Assistant Professor, English Department, Lovely Professional University, Punjab, India. 